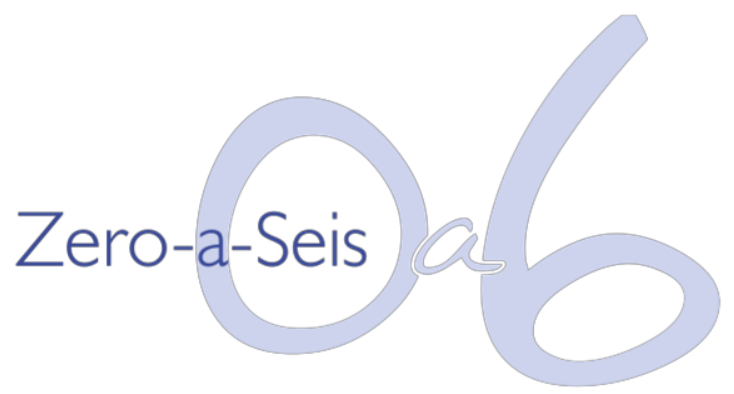

\title{
AFETO É PALAVRA MASCULINA: EXPERIÊNCIAS DE UM ESTAGIÁRIO DA EDUCAÇÃO INFANTIL NO RECÔNCAVO DA BAHIA
}

Affection is a masculine word: experiences of an intern in Child Education at Recôncavo of Bahia State - Brazil

\author{
Robervaldo Neri dos Santos PASSOS \\ Graduando em Licenciatura em Pedagogia \\ Universidade Federal do Recôncavo da Bahia \\ Amargosa, Bahia, Brasil \\ robinhoufrb2015.2ped@gmail.com \\ https://orcid.org/0000-0001-7403-9635
}

\author{
Alice Costa MACEDO \\ Professora adjunta \\ Universidade Federal do Recôncavo da Bahia \\ Amargosa, Bahia, Brasil \\ alicemacedo@ufrb.edu.br \\ https://orcid.org/0000-0002-0955-1218
}

A lista completa com informações dos autores está no final do artigo

\begin{abstract}
RESUMO
O presente relato traz a experiência acadêmica de um estudante de Pedagogia, em sua atuação no estágio de Educação Infantil na creche, no Recôncavo da Bahia, junto a uma turma de crianças de 2 anos de idade. A narrativa desta vivência contribuiu para uma reflexão sobre a presença de homens em espaços institucionais de educação e, mais especificamente, no cuidado de crianças pequenas. Tais espaços até recentemente eram ocupados quase exclusivamente por mulheres, entretanto, nos últimos anos, é perceptível a presença de um quantitativo maior de homens compartilhando a docência e outros afazeres no interior dessas instituições. Deste modo, discute-se que, apesar da existência de preconceitos, a inserção de homens na Educação Infantil pode representar alterações qualitativamente positivas no processo de interação com os demais adultos e também na educação das crianças.
\end{abstract}

PALAVRAS-CHAVE: Educação Infantil. Masculinidade. Gênero.

\section{ABSTRACT}

This present report brings forth the academic experience of a Pedagogy student on their performance at a Child Education internship on a day-care center in the city of Recôncavo - Bahia State - Brazil, with a class of 2 years old children. This experience contributed to a reflection about the presence of men in institutional spaces of education and, more specifically, care for small children. Such spaces were until recently occupied almost exclusively by women, although, in the last few years, it's noticeable the presence of a larger number of men sharing the faculty and other affairs inside these institutions. Therefore, it's discussed that, despite the existence of prejudices, the insertion of men in Child Education can represent positive change in the process of interaction with other adults and the children alike.

KEYWORDS: Child Education. Masculinity. Gender. 


\section{INTRODUÇÃO}

O propósito de apresentar este relato de experiência remete a algumas de minhas inquietações sobre as relações de gênero presentes na Educação Infantil. Em especial, eu pergunto: por que existem poucos homens nessa primeira etapa da Educação Básica? Que fatores acarretam o afastamento dos mesmos e por que, ao se inserirem nesses espaços institucionais de educação e cuidado de crianças, não há aceitação favorável? Essas são algumas questões que buscarei discutir neste relato. Contudo, antes de prosseguir, considero necessário me apresentar.

Chamo-me Robervaldo Neri dos Santos Passos, sou homem, heterossexual, negro, candomblecista, militante do movimento negro no Recôncavo da Bahia, oficineiro e contador de histórias das bonecas Abayomi, além de voluntário da Associação Criança Alegria de Viver (ACAV), localizada em uma cidade de pequeno porte no Vale do Jequiriçá. Sobre a minha formação acadêmica, cursei quatro semestres no curso de Licenciatura em Biologia na Universidade Federal do Recôncavo da Bahia (UFRB), em Cruz das Almas - BA. Nesta época, tive a oportunidade de vivenciar o PIBID (Programa Institucional de Bolsa de Iniciação à Docência) e foi naquele espaço que percebi o quanto eu queria ser professor, não no Ensino Fundamental II ou no Ensino Médio, mas na Educação Infantil.

Naquele mesmo ano (2014), prestei o ENEM (Exame Nacional do Ensino Médio) e me inscrevi no curso de Pedagogia na mesma universidade (UFRB). Em 2015, saiu o resultado, e eu passei no curso. Desisti do que eu cursava e fui iniciar uma nova batalha na Pedagogia pela Educação, confiante do que eu queria. Estou no curso de Licenciatura em Pedagogia pela Universidade Federal do Recôncavo da Bahia (UFRB), no Centro de Formação de Professores (CFP), desde Março de 2016.

$O$ fato de ser homem foi vetor de muitas situações constrangedoras relacionadas à escolha do curso de Pedagogia e igualmente por desejar ser professor da Educação Infantil. Como se sabe, a Educação Infantil, historicamente, foi e continua sendo um espaço de ocupação feminina. Assim, esses mesmos constrangimentos continuaram me causando mal-estar, ao iniciar, no terceiro semestre, o estágio na Educação Infantil.

Historicamente, as transformações na Educação Infantil não foram instantâneas. Pelo contrário, ocorreram gradativamente ao longo das décadas até que houvesse sua consolidação como a primeira etapa da Educação Básica. A presença de professores homens na Educação Infantil cresceu, sobretudo, a partir das alterações nas Leis que regem a educação brasileira (conforme citadas a seguir), pois os municípios passaram 
a realizar concursos públicos, por determinação legal, para suprir a necessidade de vagas na carreira de magistério também nas instituições voltadas para a infância.

Tais mudanças foram significativas para a valorização dos profissionais de creches e pré-escolas. A própria concepção de educação e de infância sofre constantemente alterações, uma vez que as crianças, em muitos casos, ainda são vistas como seres incapazes de pensar e de tomar decisões por si, cabendo, comumente, ao(à) professor(a) decidir por elas.

Segundo Vieira (1988), a partir de 1940, através do Departamento Nacional da Criança, a criação das creches, por exemplo, configurou-se parte de uma política de assistência à maternidade e à infância, associada a um projeto médico, sanitarista e higienista, exigido pelas novas necessidades de uma sociedade urbano-industrial que deveria propiciar meios de sobrevivência aos filhos de trabalhadores e trabalhadoras, de modo não desprovido de interesses econômicos.

Ao longo da história, outras mudanças acompanharam esse espaço que parecia se consolidar pouco a pouco como etapa importante da Educação, tal como destaca Kuhlmann Júnior (2000), quando se refere às mudanças pelas quais creches e préescolas passaram desde as décadas de 60 e 70; e posteriormente, nos anos 80 (com a Constituição de 1988) e, por fim, com a Lei de Diretrizes e Bases na década de 90 :

\begin{abstract}
Na quarta última parte dos anos 1900, a educação infantil brasileira vive intensas transformações. É durante o regime militar, que tantos prejuízos trouxe para a sociedade e para a educação brasileira, que se inicia esta nova fase, que terá seus marcos de consolidação nas definições da Constituição de 1988 e na tardia Lei de Diretrizes e Bases da Educação Nacional, de 1996. A legislação nacional passa a reconhecer que as creches e pré-escolas, para crianças de 0 a 6 anos, são parte do sistema educacional, primeira etapa da educação básica (KUHLMANN JÚNIOR, 2000, p. 6).
\end{abstract}

A Nova Lei de Diretrizes e Bases da Educação (LDB) (BRASIL, 1996) possibilitou mudanças significativas no cenário da educação, especialmente no que se refere à profissionalização e à formação de seu patrimônio humano, cada vez mais atento à nova realidade brasileira. Isso transformou, substancialmente, o perfil do(a) professo(a), o que incluiu a possibilidade de inserção de docentes do sexo masculino na Educação Infantil, através dos concursos públicos.

Por fim, atualmente, no século XXI, o debate sobre as relações de gênero nas instituições educacionais ganhou força. As produções acadêmicas sobre o assunto também assumiram relevância, de forma que muitos estudos e pesquisas vêm 
demonstrando a atuação de homens no âmbito da docência, já que as mulheres representam a maioria neste cenário, desde a Educação Infantil até o Ensino Superior.

\section{O COLO É O MUNDO TODO, NÃO CABE NA SOLEIRA DA PORTA}

A presença feminina no espaço docente da Educação Infantil é significativamente maior que a masculina. Segundo o Censo Escolar de 2017 (INEP, 2018), as mulheres são maioria absoluta na Educação Infantil, representando 96,6\% dos educadores que atuam com bebês e crianças de até $5 / 6$ anos de idade. Desde o princípio de sua criação, as creches, por exemplo, incluíam o trabalho de mulheres orientadas a disciplinar as mães e a cuidar de suas crianças, nos preceitos da puericultura, constituindo-se "como um dispositivo de normatização da relação mãe/filho nas classes populares" (VIEIRA, 1988, p. 4).

Ainda de acordo com Vieira (1988), entre as décadas de 1940 e 1980, as mulheres foram ocupando cada vez mais espaço no mercado de trabalho, o que leva ao aumento da necessidade de buscar lugares adequados e seguros para deixar seus filhos (ou seja, em uma instituição educacional e com outras mulheres). Assim, a criação e o desenvolvimento das instituições de Educação Infantil estão associados, no contexto social, a uma espécie de "mal necessário", ou um "recurso ligado à pobreza", quando mulheres das classes populares renunciam ao lar para garantir a sobrevivência de suas famílias (VIEIRA, 1988).

Carvalho (1999) discute a presença feminina na Educação Infantil a partir de uma reflexão minuciosa sobre a categoria "cuidado", quase sempre associada às mulheres. Thomasi e Venturini (2013, p. 8) discutem que: "com a entrada, praticamente total, das mulheres no magistério da Educação Infantil, este se feminizou, tendo atributos associados às mulheres, como amor, cuidado, sensibilidade, delicadeza, entre outros".

[...] o trato com as emoções seria considerado terreno feminino, o que permite apreender melhor as dimensões de feminização da Educação Infantil e dos anos iniciais do Ensino Fundamental. As emoções e o cuidado infantil são tidos como femininos e, feminino é entendido como sinônimo de mulheres (THOMASI; VENTURINI, 2013, p. 8-9).

É nesse sentido que se justifica o título deste relato, ao associar a afetividade ao universo masculino de atuação profissional, quando se propõe um jogo lúdico com a palavra "afeto" que, na língua portuguesa, é um substantivo masculino. 
Pode-se compreender que o trabalho com a Educação Infantil é cercado de atributos ligados às mulheres, e compreendidos como incomuns nos homens, a exemplo do que as próprias autoras apresentam relativamente ao amor, cuidado, delicadeza, sensibilidade, dentre outros. Sentimentos estes considerados essenciais para o cuidado de crianças e entendidos como inerentes às mulheres.

É diante desse universo que aqui retomo o meu relato de experiência na posição de estagiário homem no espaço da Educação Infantil, a fim de tecer um diálogo frutífero com tal discussão. Em meu primeiro contato com as crianças observei nelas expressões de curiosidade ao me ver, ao lado de minha colega de estágio (uma garota). Nós éramos pessoas estranhas em seu espaço. Contudo, não demorou muito para se acostumarem com a gente, e nós com elas.

Na referida experiência, confesso que me sentia em um espaço ao mesmo tempo hostil e acolhedor. Achei que eu estaria preparado para tudo, pois eu já esperava o preconceito que viria, não das crianças, mas dos adultos. Contudo, eu não estava preparado, e talvez nunca esteja, para lidar com as situações de preconceito e discriminação, pois a teoria é muito diferente da prática, ou seja, da realidade sentida na pele.

O estágio era dividido em três etapas de atuação prática nas Escolas Municipais de Educação Infantil em uma cidade de pequeno porte no Recôncavo da Bahia: uma fase de observação (em que estávamos presentes, conhecendo as crianças, as educadoras e o ambiente); o período que chamávamos de coparticipação em que já prevíamos um vínculo com as crianças, a escola e as educadoras e, por isso, nos disponibilizávamos a auxiliá-las em todos os momentos em que elas demandavam; e, por fim, a fase da regência, em que propúnhamos, após aprovação do nosso plano na reunião da coordenação pedagógica, atividades educativas com as crianças. Devo destacar que, nas três etapas, o estagiário acabava sendo, inevitavelmente, solicitado a auxiliar com atividades relacionadas ao cuidado.

Perfazendo esse caminho vivenciando, descrevo, a seguir, um dos momentos em que, pela primeira vez, surgiu em mim essa sensação de estar diante de um contexto de hostilidade: a diretora da instituição me convidou, assim como a professora orientadora de estágio, para uma conversa. A referida gestora nos relatou que o pai de uma criança, quando veio trazer a filha para a escola, questionou a minha presença na sala de aula: primeiro, ele quis saber se eu também era pai de alguma das crianças, ao que ela respondeu "não, ele é um estagiário". A diretora contou esse episódio deixando 
claro que houve um desconforto em relação à permanência de um homem em meio às crianças.

Diante disso, ela me fez um pedido: no momento em que eu fosse solicitado a acompanhar as crianças até o banheiro para a higiene delas, eu deveria ficar na sala para evitar atritos entre as famílias, pois não seria interessante um homem entrar no banheiro com uma criança. Fiquei sem saber o que falar, e agora volto ao que eu disse anteriormente: realmente a teoria é muito diferente da prática, nunca estamos preparados(as) para o que nos espera lá na frente. A minha professora do estágio ainda buscou compreender melhor este ponto a fim de fomentar uma reflexão, perguntando à diretora da escola quem acompanharia os meninos até o banheiro, ao que ela respondeu que seria a auxiliar de classe e a outra estudante (minha colega de estágio). Após este momento eu fiquei sem reação, confesso que me desanimei um pouco.

Em contrapartida, logo em seguida, recuperei as minhas forças. Num momento, durante o estágio, novamente a diretora da escola me chamou em sua sala. Percebi que ela estava um pouco sem graça, e me pediu para evitar que eu deixasse as crianças sentarem no meu colo, porque um familiar poderia chegar na sala e não gostar. Este foi o segundo momento em que eu quis dizer algo, contudo não sabia como falar, afinal estava ali como estagiário e não como regente.

Mais tarde pensei sobre aquelas palavras e parei para refletir: seria impossível impedir que as crianças sentassem em meu colo quando fossem fazer uma atividade coletiva com elas ou quando alguma delas estivesse chorando por qualquer motivo, necessitando de afeto, independentemente de sua idade. Em meio ao redemoinho de apreensões, mas sempre contando com palavras de afeto da professora orientadora de estágio da universidade, que pôde me acompanhar e dividir um pouco das minhas angústias, fui concluindo o estágio, tentando não levar as crianças ao banheiro mesmo quando elas me pediam. Às vezes eu as levava até a porta e ali esperava.

Em outros momentos, eu as colocava em meu colo quando elas pediam, mesmo contrariando o pedido da diretora, não por querer um enfrentamento com a direção ou com os familiares das crianças, mas por não ter como negar isso. Eu acredito ser impossível contribuir na educação de uma pessoa, independentemente de sua idade, sem doar afeto. Meu desejo é que a minha presença naquele espaço tenha contribuído para construir uma imagem afetiva do universo masculino para aquelas crianças. Espero que elas possam entender que homens também doam, expressam e recebem afeto e igualmente podem ser sensíveis. 
A concepção de que o trabalho na Educação Infantil deve ser ocupado por mulheres é proveniente de uma estereotipia, vinculada à máxima universalizante: "toda mulher tem por si um instinto materno natural". Essa ideia a coloca como a única capaz de trabalhar com crianças, além de naturalizar um modelo de feminino fixado em padrões binários de gênero. Além disso, deve-se problematizar a perspectiva "sexualizada" ou "erótica" do afeto masculino, inclusive no âmbito da educação e do trabalho docente. É como se o afeto não pudesse ser "masculino" e, quando proveniente de homens, não estaria dissociado de conotações sexuais.

Os estereótipos são os resultados do preconceito; é uma suposição simplista sobre um determinado grupo ou uma forma de rotular o mesmo, podem ser suposições positivas do tipo 'toda mulher é carinhosa', ou negativas, como 'todo baiano é preguiçoso'. Enquanto as definições dadas por alguns estudos são das mais diversas, a maioria concorda que muitas se tratam de pré-julgamentos normalmente negativos sobre determinado grupo (MARTINS; SILVA, 2016, p. 5).

As pessoas se rotulam e rotulam as outras através dos estereótipos, ou seja, daquilo que se é visível ao olho, e assim a nossa sociedade foi e está se formando. Em relação à educação e à escolarização não é diferente: esta não é somente uma realidade da creche na qual eu realizei o meu estágio, e muito menos do contexto do Recôncavo da Bahia, é uma realidade nacional, e quiçá mundial. Existem papéis predefinidos em nossa sociedade, há padrões, e quando se foge disso você se torna condenado e perseguido até que se adeque à norma social. Com isso, luta-se contra a maré e contra toda esta normatividade, pois sempre existe outro lado a ser escolhido, basta ter coragem e força para lutar e resistir.

Souza (2015), ao observar os critérios utilizados pelas próprias crianças da Educação Infantil na opção entre professor e professora, observa que o gênero não aparece (como era de se esperar) como método de escolha.

\footnotetext{
Quando as crianças são incitadas a escolher uma opção de creche caso tivessem de escolher entre as três que Ihe foram apresentadas (entre uma creche com apenas professores, somente com professoras ou com ambos), essas quatro crianças se dividem em suas opiniões orientando suas escolhas pela experiência de castigo que elas têm vivenciado. William e Fabrício escolheriam a creche só com homens porque eles não os põem de castigo. Carla escolheria uma creche com professores e professoras, pois, segundo ela tanto homens como mulheres põem de castigo. Já para Virginia seria melhor creche só com professoras, pois "elas não botam de castigo e eles botam".

Sendo os castigos critérios utilizados pelas crianças para avaliar o ingresso e trajetória do professor na instituição, é possível inferir que, pelo menos para essas quatro crianças, não é o gênero um elemento definidor das suas escolhas, mas a prática pedagógica que vivenciam, ou seja, o modo como o professor interage com elas no dia-a-dia das atividades no CEI. Essa alusão ao castigo pelas crianças não é uma novidade desta pesquisa (SOUZA, 2015, p. 10).
} 
A partir desse trecho, pode-se observar que as crianças não escolhem qual profissional da educação infantil é melhor, por ser homem ou mulher, mas sim pela postura deste ou desta dentro da sala de aula e/ou outros critérios que porventura sejam importantes naquele momento educativo.

Sobre o Referencial Curricular Nacional para a Educação Infantil (RCNEI), em momento nenhum há uma linha sequer que especifique direta ou indiretamente que o profissional da educação infantil tem que ser do sexo feminino. Referente aos docentes, podemos observar as orientações para os(as) mesmos(as) de como se deve atuar na sala de aula com as crianças.

Aquilo que é definido como masculino e feminino só passa a funcionar como elemento de escolha das crianças quando estas estão sob o auspício destas regulações. Na Educação Infantil não é diferente, pois, somente quando se impõem modelos sociais na infância, é que estas crianças revelarão os efeitos destas normatizações. Podemos ver isto quando uma menina se destaca num papel socialmente masculino. É justamente neste momento que o seu gênero é posto em dúvida pelos adultos, como podemos observar no seguinte relato:

\begin{abstract}
Uma situação escolar, relatada por Deborah Britzman (1996), pode ser interessante para a compreensão destas questões: uma menina, desempenhando com muito sucesso a função de goleira num jogo de futebol feminino, é questionada por um pai do time adversário, que exige "provas" do seu gênero. 0 exemplo serve para refletirmos a respeito de quais "características", como diz Deborah, são levadas em consideração a fim de que se possa identificar o gênero "normal" ou para que se torne o gênero "normalizado"- Além disso, a situação também nos permite pensar a respeito do que é feito para "garantir" que as crianças "obtenham o gênero "correto". A estudiosa especula sobre uma série de possíveis caminhos que poderá seguir essa menina: a possibilidade de que seu comportamento seja construído como "desviante"; a de que ela se torne "o projeto pedagógico" de um professor ou professora o/a qual irá, então, tentar "refeminizála"; ou, quem sabe, a de que ela tenha chance de encontrar pessoas, livros ou situações que the mostrem outras mulheres que ousaram transgredir a normalização do gênero para "construir novos desejos e novos estilos" (LOURO, 1997, p. 82).
\end{abstract}

Desviar é afrontar as expectativas de gênero, postura que passa a ser alvo das correções e punições. De toda forma, isto nos revela as normas impostas aos corpos a partir dos modelos e de suas hierarquizações, indicando que há, sim, pedagogias de regulação dos gêneros. 


\section{CONSIDERAÇÕES FINAIS}

Diante do que já foi discutido anteriormente neste relato, a concepção de docência em qualquer das etapas da educação parece ser, por vezes, deturpada desde o século XVIII, no contexto da Revolução Industrial. À época, a creche servia às mães que trabalhavam nas fábricas como operárias para deixarem suas crianças, onde seriam alimentadas, banhadas e postas para dormir. Este era e ainda é um trabalho considerado feminino e está longe de resumir tudo o que fazemos na Educação Infantil. Este pensamento vem se mantendo até os dias atuais por muitas pessoas, embora o debate e o questionamento estejam ganhando cada vez mais força.

A discussão sobre a presença do homem na Educação Infantil está longe de um final, pois ela entra em algo muito forte em nosso contexto, que são os valores padronizados. Quando algo foge deste padrão, as pessoas de imediato se manifestam contra esta mudança. Para parcela da sociedade, o homem não tem o necessário para trabalhar com crianças.

Todavia, tenho esperanças de que mudanças ocorram e novos horizontes se abram, de modo que possamos ser vistos(as) e escutados(as) nas profissões que escolhemos pelas nossas habilidades profissionais e não pelo nosso gênero, afinal afeto não é só palavra, é gesto (também) masculino.

\section{REFERÊNCIAS}

BRASIL. Constituição (1988). Constituição da República Federativa do Brasil. Brasília, DF: Senado, 1988.

BRASIL. Lei de Diretrizes e Bases da Educação Nacional. Lei número 9394, 20 de dezembro de 1996.

BRASIL. Ministério de Educação e do Desporto. Referencial curricular nacional para educação infantil. Brasília, DF: MEC, 1998.

CARVALHO, Marília Pinto de. No coração da sala de aula: gênero e trabalho docente nas séries iniciais. São Paulo: Xamã, 1999.

INEP. Instituto Nacional de Estudos e Pesquisas Educacionais. Anísio Teixeira. Ministério da Educação. Disponível em: <http://www.enem.inep.gov.br/>. Acesso em: 06 mai. 2020.

KUHLMANN Jr., Moysés. Histórias da educação infantil brasileira. Revista Brasileira de Educação, n. 14, p. 5-18, 2000. Disponível em: <http://www.scielo.br/pdf/rbedu/n14/n14a02>. Acesso em: 19 set. 2019. 
LOURO, Guacira Lopes. Gênero, sexualidade e educação: uma perspectiva pós estruturalista. Petrópolis, RJ: Vozes, 1997.

MARTINS, Viviane Lima; SILVA, Júlio Régis da. O professor homem na educação infantil: Um olhar acerca do preconceito. Revista Intraciência, n. 11, p. 01-23, 2016. Disponível em:

<http://www.faculdadedoguaruja.edu.br/revista/downloads/edicao112016/Artigo02.p df>. Acesso em: 20 abr. 2017.

SOUZA, José Edilmar de. Homem docência com crianças pequenas: O olhar das crianças de um centro de educação infantil. 37a Reunião Nacional da ANPEd, Florianópolis: UFSC, 2015. Disponível em:

<http://www.anped.org.br/sites/default/files/trabalho-gt07-4232.pdf>. Acesso em: 19 set. 2019.

THOMASI, Katia Barroso; VENTURINI, Angela Maria. A feminização na educação infantil: uma questão de gênero. Revista Científica Digital da FAETEC, v. 1, n. 1, p. 1-15, 2013. Disponível em:

<http://www.faetec.rj.gov.br/desup/index.php/edutec>. Acesso em: 25 ago. 2020.

VIEIRA, Lívia Maria Fraga. Mal necessário: creches no Departamento Nacional da Criança (1940-1070). Cadernos de Pesquisa, n. 67, p. 3-16, 1988.

\section{NOTAS}

AFETO É PALAVRA MASCULINA: EXPERIÊNCIAS DE UM ESTAGIÁRIO DA EDUCAÇÃO INFANTIL NO RECÔNCAVO DA BAHIA

Affection is a masculine word: experiences of an intern in Child Education at Recôncavo of Bahia State Brazil

Alice Costa Macedo
Professora adjunta
Universidade Federal do Recôncavo da Bahia
Amargosa, Bahia, Brasil
alicemacedo@ufrb.edu.br
https://orcid.org/0000-0002-0955-1218

Robervaldo Neri dos Santos Passos

Graduando em Licenciatura em Pedagogia Universidade Federal do Recôncavo da Bahia

Amargosa, Bahia, Brasil robinhoufrb2015.2ped@gmail.com https://orcid.org/0000-0001-7403-9635 (1)

Endereço de correspondência do principal autor

Avenida Nestor de Melo Pita, 535, Centro, Amargosa - BA, Brasil, CEP 45300-000.

AGRADECIMENTOS

Inserir os agradecimentos a pessoas que contribuíram com a realização do manuscrito.

CONTRIBUIÇÃO DE AUTORIA

Concepção e elaboração do manuscrito: Todos os autores contribuíram substancialmente. 
Coleta de dados: R. N. S. Passos.

Análise de dados: Todos os autores contribuíram substancialmente.

Discussão dos resultados: Todos os autores contribuíram substancialmente.

Revisão e aprovação: Todos os autores contribuíram substancialmente.

CONJUNTO DE DADOS DE PESQUISA

Todo o conjunto de dados que dá suporte aos resultados deste estudo foi publicado no próprio artigo.

\section{FINANCIAMENTO}

Não se aplica.

\section{CONSENTIMENTO DE USO DE IMAGEM}

Não se aplica.

\section{APROVAÇÃo de COMITÊ de ÉtICA EM PESQUISA \\ Não se aplica.}

\section{CONFLITO DE INTERESSES}

Informar conflitos de interesse: financeiros, pessoais, entre possíveis revisores e editores, e/ou possíveis vieses temáticos. Se não houver, mencionar: Não se aplica. Para mais informações: https://www.abecbrasil.org.br/arquivos/whitepaper CSE.pdf

LICENÇA DE USO - uso exclusivo da revista

Os autores cedem à Zero-a-Seis os direitos exclusivos de primeira publicação, com o trabalho simultaneamente licenciado sob a Licença Creative Commons Attribution (CC BY) 4.0 International. Esta licença permite que terceiros remixem, adaptem e criem a partir do trabalho publicado, atribuindo o devido crédito de autoria e publicação inicial neste periódico. Os autores têm autorização para assumir contratos adicionais separadamente, para distribuição não exclusiva da versão do trabalho publicada neste periódico (ex.: publicar em repositório institucional, em site pessoal, publicar uma tradução, ou como capítulo de livro), com reconhecimento de autoria e publicação inicial neste periódico.

PUBLISHER - uso exclusivo da revista

Universidade Federal de Santa Catarina. Núcleo de Estudos e Pesquisas da Educação na Pequena Infância - NUPEIN/CED/UFSC. Publicação no Portal de Periódicos UFSC. As ideias expressadas neste artigo são de responsabilidade de seus autores, não representando, necessariamente, a opinião dos editores ou da universidade.

EDITORES - uso exclusivo da revista Márcia Buss-Simão e Kátia Agostinho.

HISTÓRICO - uso exclusivo da revista

Recebido em: 16-07-2020 - Aprovado em: 15-09-2020 